\title{
Pola Sirkulasi Arus Dan Salinitas Perairan Estuari Sungai Kapuas Kalimantan Barat
}

\author{
Muh.Ishak Jumarang 1), Muliadi 1), Nining Sari Ningsih 2), Safwan Hadi2), Dian Martha') \\ 1) Program Studi Fisika FMIPA Universitas Tanjungpura Pontianak \\ 2) Program Studi Oseanografi FITB, ITB Bandung
}

\begin{abstract}
Abstrak
Telah dilakukan penelitian untuk mengkaji pola sirkulasi arus dan salinitas perairan estuari sungai Kapuas yang dibangkitkan oleh pasang surut, gaya pembangkit angin dan discharge sungai. Pada studi ini digunakan model numerik hidrodinamika MIKE 21 yang dikembangkan oleh DHI Water \& Environment untuk mensimulasikan pola sirkulasi arus dan salinitas. Pola sirkulasi arus hasil simulasi menunjukkan pada kondisi pasang tertinggi, massa air bergerak dari utara ke selatan hingga masuk ke badan sungai sedangkan pada kondisi dan surut terendah massa air bergerak ke arah yang berlawanan (dari selatan ke utara) dan air mengalir dari sungai ke luar menuju lepas pantai. Pergerakan massa air pada kisaran kecepatan 0,05 sd 0,7 m/s. Pola sirkulasi arus baik saat purnama maupun perbani menunjukkan kesesuaian pola dan yang membedakan adalah besarnya kecepatan arus. Sebaran salinitas pada kondisi purnama (pasang tertinggi dan surut terendah) cenderung memiliki pola dan nilai yang sama dengan nilai salinitas dominan pada kisaran 33,2 s.d 33,4 PSU. Demikian pula pada kondisi perbani.
\end{abstract}

Kata Kunci: Sirkulasi arus, pasang surut, Estuari, Kapuas

\section{Pendahuluan}

\subsection{Latar Belakang}

Sungai Kapuas yang merupakan sungai terpanjang di Indonesia (1.143 km) menjadi urat nadi bagi kehidupan masyarakat Kalimantan Barat yaitu sebagai sarana transportasi sungai, sumber irigasi, sumber perikanan dan sebagainya. Dewasa ini, terdapat berbagai masalah lingkungan yang dihadapi Sungai Kapuas, antara lain masalah naiknya kadar garam musiman di sekitar muara, peningkatan endapan lumpur, erosi, banjir, dan pendangkalan jalur perkapalan ke pelabuhan sungai.

Daerah estuari Sungai Kapuas merupakan daerah yang sangat kompleks karena adanya pengaruh seperti sapuan arus, hempasan ombak dan pasang surut laut (pasut). Dengan demikian, wilayah tersebut memiliki peluang untuk mengalami perubahan (dalam skala ruang dan waktu). Interaksi antara aliran air dari Sungai Kapuas dan arus pasang surut yang masuk dari laut berpengaruh terhadap dinamika hidrodinamika, intrusi salinitas, dan proses transpor sedimen.

Pemahaman tentang pentingnya pengelolaan daerah muara membutuhkan pananganan yang berkelanjutan (sustainable). Salah satu aspek lingkungan yang penting untuk di ketahui agar pengelolaan daerah muara dapat dilaksanakan dengan tepat adalah dengan memahami dinamika perairan. Sebagai salah satu upaya memahami dinamika perairan (sirkulasi arus dan salinitas) model hidrodinamika akan digunakan untuk mensimulasikan dinamika perairan. Gaya pembangkit (generating forces) arus yang akan digunakan adalah pasang surut (pasut), discharge sungai dan angin.

\subsection{Tujuan Penelitian}

Studi ini bertujuan untuk memodelkan dan mengkaji pola sirkulasi arus dan salinitas estuari Sungai Kapuas yang dibangkitkan oleh pasang surut, discharge sungai dan angin. Manfaat dari hasil penelitian diharapkan dapat digunakan sebagai input dalam pengelolaan lingkungan di sekitar daerah estuari Sungai Kapuas, sehingga pembangunan yang dilakukan merupakan pembangunan yang terencana dan berwawasan lingkungan. 


\section{Metodologi}

\subsection{Model Hidrodinamika}

Pergerakan massa air (hidrodinamika) di suatu perairan dapat dipelajari dengan menggunakan hukum kekekalan massa (kontinuitas) dan kekekalan momentum. Pada studi ini digunakan model numerik hidrodinamika 2 dimensi menggunakan MIKE 21 yang dikembangkan oleh DHI Water \& Environment untuk mensimulasikan pola sirkulasi arus dan salinitas. MIKE 21 menggunakan fleksibel mesh dan telah banyak diaplikasikan dalam bidang oseanografi daerah coastal dan estuari.

Persamaan kontinuitas:

$$
\frac{\partial h}{\partial t}+\frac{\partial h \bar{u}}{\partial x}+\frac{\partial h \bar{v}}{\partial y}=h S
$$

Persamaan momentum dalam arah $\mathrm{x}$ dan $\mathrm{y}$ :

$$
\begin{aligned}
& \frac{\partial h \bar{u}}{\partial t}+\frac{\partial h \bar{u}^{2}}{\partial x}+\frac{\partial h \bar{v} \bar{u}}{\partial y}=f \bar{v} h-g h \frac{\partial \eta}{\partial x}-\frac{g h^{2}}{2 \rho_{0}} \frac{\partial \rho}{\partial x} \\
& +\frac{\tau_{s x}}{\rho_{0}}-\frac{\tau_{b x}}{\rho_{0}}+\frac{\partial}{\partial x}\left(h T_{x x}\right)+\frac{\partial}{\partial y}\left(h T_{x y}\right)+h u_{s} S
\end{aligned}
$$

$$
\begin{aligned}
& \frac{\partial h \bar{v}}{\partial t}+\frac{\partial h \bar{u} \bar{v}}{\partial x}+\frac{\partial h \bar{v}^{2}}{\partial y}=f \bar{u} h-g h \frac{\partial \eta}{\partial y}-\frac{g h^{2}}{2 \rho_{0}} \frac{\partial \rho}{\partial y} \\
& +\frac{\tau_{s y}}{\rho_{0}}-\frac{\tau_{b y}}{\rho_{0}}+\frac{\partial}{\partial x}\left(h T_{x y}\right)+\frac{\partial}{\partial y}\left(h T_{y y}\right)+h v_{s} S
\end{aligned}
$$

dengan $t$ menyatakan waktu; $\bar{u}$ dan $\bar{v}$ masingmasing menyatakan kecepatan arus dalam arah $x$ dan $y$ yang dirata-ratakan terhadap kedalaman $h \bar{u}=\int_{-d}^{\eta} u d z$ dan $h \bar{v}=\int_{-d}^{\eta} v d z ; \eta$ adalah elevasi muka air laut; $h=\eta+d$ adalah kedalaman total perairan; $f=2 \Omega \sin \phi$ parameter Coriolis; $g$ percepatan gravitasi bumi; $\rho$ densitas air; $p_{a}$ tekanan atmosfer; $S$ adalah magnitudo discharge sungai. $T_{i j}$ menyatakan gesekan viskos masing-masing $T_{x x}=2 A \frac{\partial \bar{u}}{\partial x}, \quad T_{x y}=A\left(\frac{\partial \bar{u}}{\partial y}+\frac{\partial \bar{v}}{\partial x}\right)$ dan
$T_{y y}=2 A \frac{\partial \bar{v}}{\partial y} ; \quad \tau_{s x}, \tau_{s y} \quad$ adalah stress permukaan dalam arah $x$ dan $y$ dan $\tau_{b x}, \tau_{b y}$ adalah stress dasar dalam arah $x$ dan $y$.

\subsection{Desain Simulasi}

Daerah penelitian difokuskan di daerah hilir Sungai Kapuas, Propinsi Kalimantan Barat, dimana daerah model meliputi $1^{\circ} \mathrm{LU}-0^{\circ} 30^{\prime} \mathrm{LS}$ dan $108^{\circ} 30^{\prime} \mathrm{BT}-109^{\circ}$ 30' BT, seperti yang terlihat pada Gambar 1 . Data batimetri diperoleh dari peta batimetri Kalimantan - Pantai Barat, Dinas HidroOseanografi tahun 2005. Daerah model didiskritisasi dengan jumlah elemen 10645 dengan ukuran grid bervariasi mulai $200 \mathrm{~m}$ di bagian sungai dan muara - muara Sungai Kapuas hingga $25 \mathrm{~km}$ dari batas muara sungai. Simulasi dilakukan pada rentang 1 - 19 Januari 2009, dimana bulan tersebut mewakili musim barat. Domain model terdiri dari tiga batas terbuka, yaitu batas terbuka utara, barat dan selatan dan pada tiap titik di batas terbuka ini digunakan elevasi pasang surut yang diramalkan dengan Tidal Model Driver (TMD). Discharge sungai (hulu) diberikan data sintetik yaitu 1568,7 $\mathrm{m}^{3} / \mathrm{s}$, sedangkan data angin diperoleh dari NCEP (National Centers for Environmental Prediction) dan diberikan seragam untuk seluruh domain model tetapi bervariasi terhadap waktu (angin 6 jam-an). Koefisien gesekan dasar menggunakan koefisien Manning $32 \mathrm{~m}^{1 / 3} / \mathrm{s}$ dan untuk suku turbulensi horizontal digunakan koefisien Smagorinsky dengan nilai konstanta 0,28.

Simulasi dilakukan dengan skenario, pasut, discharge sungai dan angin sebagai pembangkit arus. Pada skenario yang dilakukan, kecepatan arus hasil model diverifikasi dengan hasil prediksi Tidal Model Driver (TMD). Titik - titik verifikasi tersebut diperlihatkan Gambar 1. Pemilihan waktu cuplik pasang surut mengacu pada titik A pada Gambar 1. 


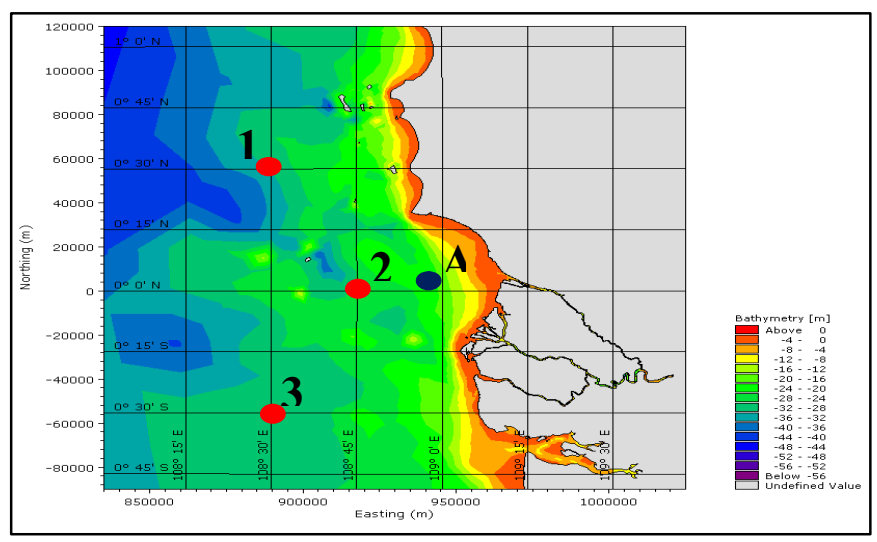

Gambar 1. Titik-titik verifikasi ditandai dengan nomor 1, 2, dan 3, acuan waktu cuplik pasang surut ditandai dengan titik

\section{Hasil Dan Pembahasan}

\subsection{Verifikasi sirkulasi Arus Laut}

Pola sirkulasi arus hasil model di titik 2 menunjukkan kesesuaian dengan hasil model prediksi TMD (Gambar 2). Sebaliknya, pada titik 3 pola arus lebih besar dibandingkan dengan hasil model prediksi TMD (Gambar 3).

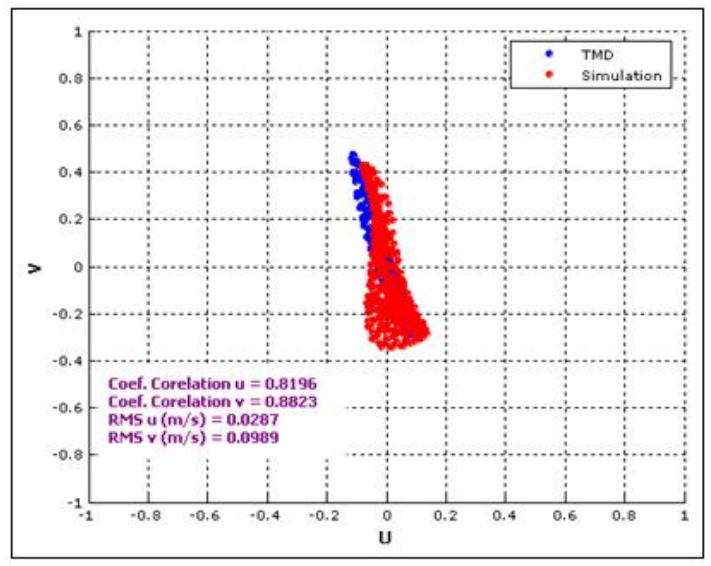

Gambar 2 Verifikasi arus hasil model (merah) terhadap TMD (biru) di titik 2

\subsection{Hasil Simulasi Pola Arus Pasang Surut}

Setelah dilakukan verifikasi model, selanjutnya dilakukan simulai arus. Hasil simulasi arus merupakan nilai yang dirataratakan terhadap kedalaman (2D). Berdasarkan simulasi ini diperoleh informasi mengenai pola sirkulasi arus berdasarkan kondisi pasut yang terjadi.

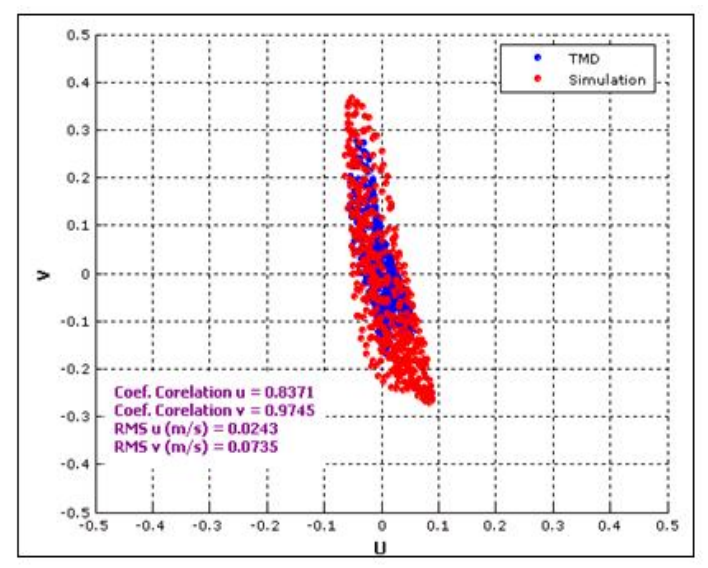

Gambar 3 Verifikasi arus hasil model (merah) terhadap TMD (biru) di titik 3

\subsubsection{Pola Sirkulasi Arus dan Salinitas pada saat Pasut Purnama}

\section{a. Pasang tertinggi purnama}

Pola sirkulasi arus dan salinitas pada kedalaman $0,2 \mathrm{~h}$ saat pasang tertinggi purnama yang diperoleh dari hasil simulasi model dapat dilihat pada Gambar 4. Pada saat pasang tertinggi untuk kondisi purnama pola sirkulasi arus permukaan yang dibangkitkan oleh pasut, angin dan discharge sungai secara umum memperlihatkan arus bergerak ke arah selatan dengan intensitas yang semakin 
bertambah di bagian selatan daerah model. Di bagian utara daerah model, arus cenderung kecil dan membentuk pola sirkulasi berbentuk pusaran berlawanan arah putaran jarum jam. Pada bagian selatan daerah model, arus bergerak ke arah Tenggara. Kisaran nilai kecepatan arus 0,05 s.d 0,3 m/s.

Salinitas maksimum pada saat pasang tertinggi terdapat pada bagian utara daerah model (33,2 s.d 33,4 PSU). Secara umum, salinitas cenderung seragam dalam arah yang sejajar garis pantai. Salinitas minimum (kurang dari 30 PSU) dijumpai pada daerah sekitar muara sungai dan semakin besar menjadi 33,2 PSU seiring bertambahnya jarak dari muara sungai. Rendahnya salinitas di daerah muara sungai disebabkan oleh suplai air tawar dari hulu Sungai Kapuas.

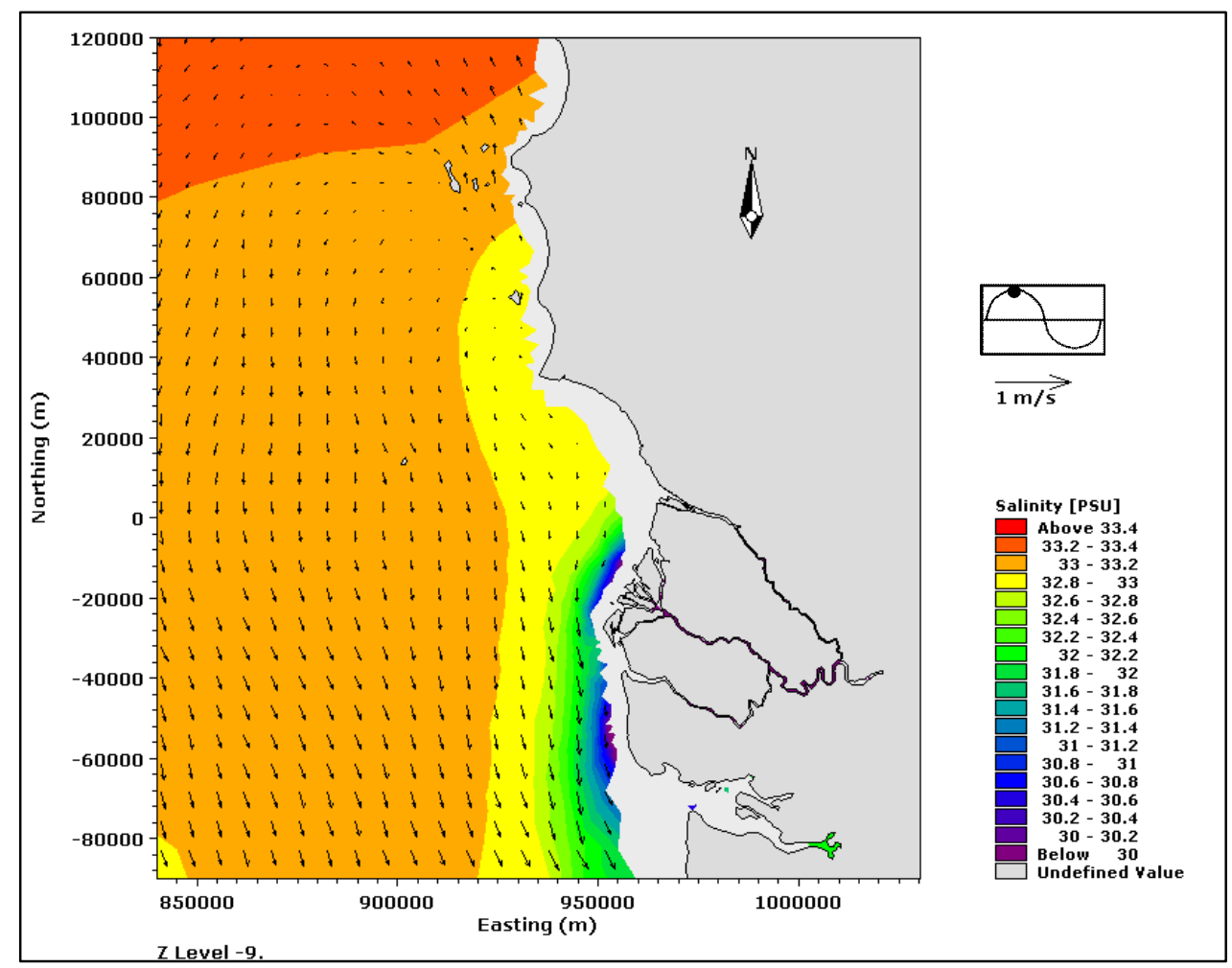

Gambar 4. Pola sirkulasi arus dan sebaran salinitas pada saat air pasang tertinggi purnama pada $0.2 \mathrm{~h}$ (bulan Januari)

\section{b. Surut terendah purnama}

Gambar 5 menunjukkan bahwa pada saat surut terendah yang terjadi pada kondisi pasut Purnama, pola sirkulasi arus yang dibangkitkan oleh pasut, angin dan discharge sungai menunjukkan pergerakan arus ke arah utara. arus bergerak ke arah utara dengan kecepatan sangat kecil $(0,1 \mathrm{~m} / \mathrm{s}$ s.d $0,2 \mathrm{~m} / \mathrm{s})$, dan semakin membesar di bagian utara daerah model. Pola sirkulasi arus ini terjadi pula untuk arus susur pantai, kecuali pada bagian utara daerah model, terlihat adanya arus susur pantai yang bergerak kearah selatan.

Hasil simulasi model pada Gambar 5 menunjukkan kecenderungan sebaran salinitas saat surut terendah purnama yang sama dengan saat surut tertinggi purnama 


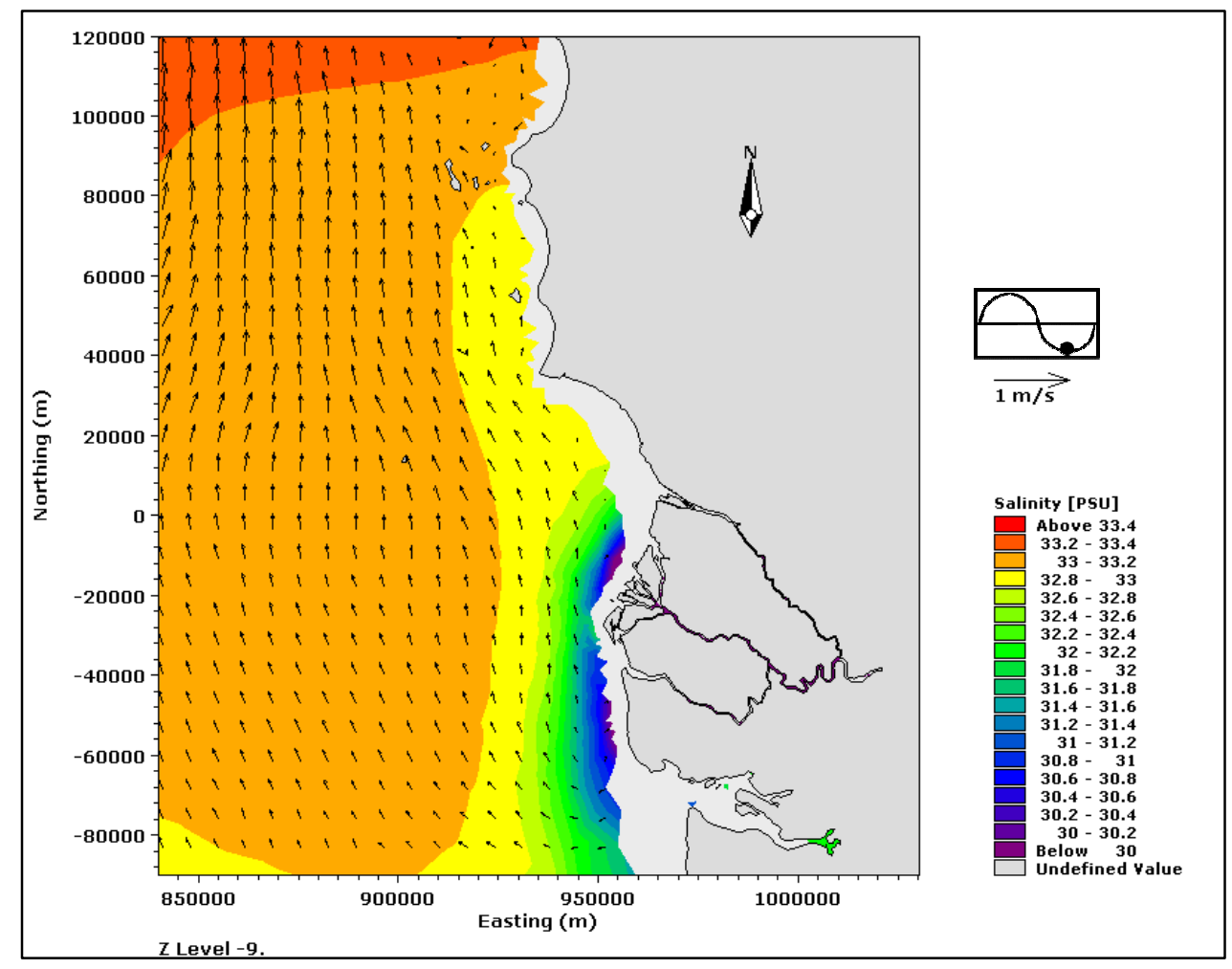

Gambar 5. Pola sirkulasi arus dan sebaran salinitas pada saat air surut terendah purnama pada $0.2 \mathrm{~h}$ (bulan Januari)

\subsubsection{Pola Sirkulasi Arus dan Salinitas pada saat Pasut Perbani \\ a. Pasang tertinggi perbani \\ Pola sirkulasi arus pada saat pasang} tertinggi perbani, kecepatan arus lebih rendah jika dibandingkan dengan saat pasang tertinggi purnama. Namun demikian, tidak terjadi perbedaan arah arus yang signifikan. Perbedaan terjadi di bagian utara daerah model, tidak nampak lagi adanya pola sirkulasi yang berlawanan arah jarum jam seperti pada saat pasang tertinggi purnama. Pada saat pasang tertinggi perbani, massa air bergerak ke arah selatan di seluruh daerah model dengan kecepatan $0,05 \mathrm{~m} / \mathrm{s}$ s.d $0,1 \mathrm{~m} / \mathrm{s}$ (Gambar 6).

Sebaran salinitas rata-rata pada kedalaman $0,2 \mathrm{~h}$ menunjukkan adanya peningkatan salinitas di daerah utara daerah model jika dibandingkan dengan saat pasang tertinggi untuk kondisi purnama. Di daerah utara daerah model, salinitas lebih besar dari 33,4 PSU dan terus berkurang ke arah selatan. Salinitas di daerah muara Sungai Kapuas menunjukkan pola yang sama dengan kondisi pasut lainnya, yakni lebih rendah dibandingkan daerah model lainnya. Salinitas daerah muara Sungai Kapuas pada saat pasang tertinggi perbani menunjukkan nilai yang lebih tinggi (31,6 PSU) dibandingkan pada saat purnama yang berada pada kisaran kurang dari 30 PSU (Gambar 6). 


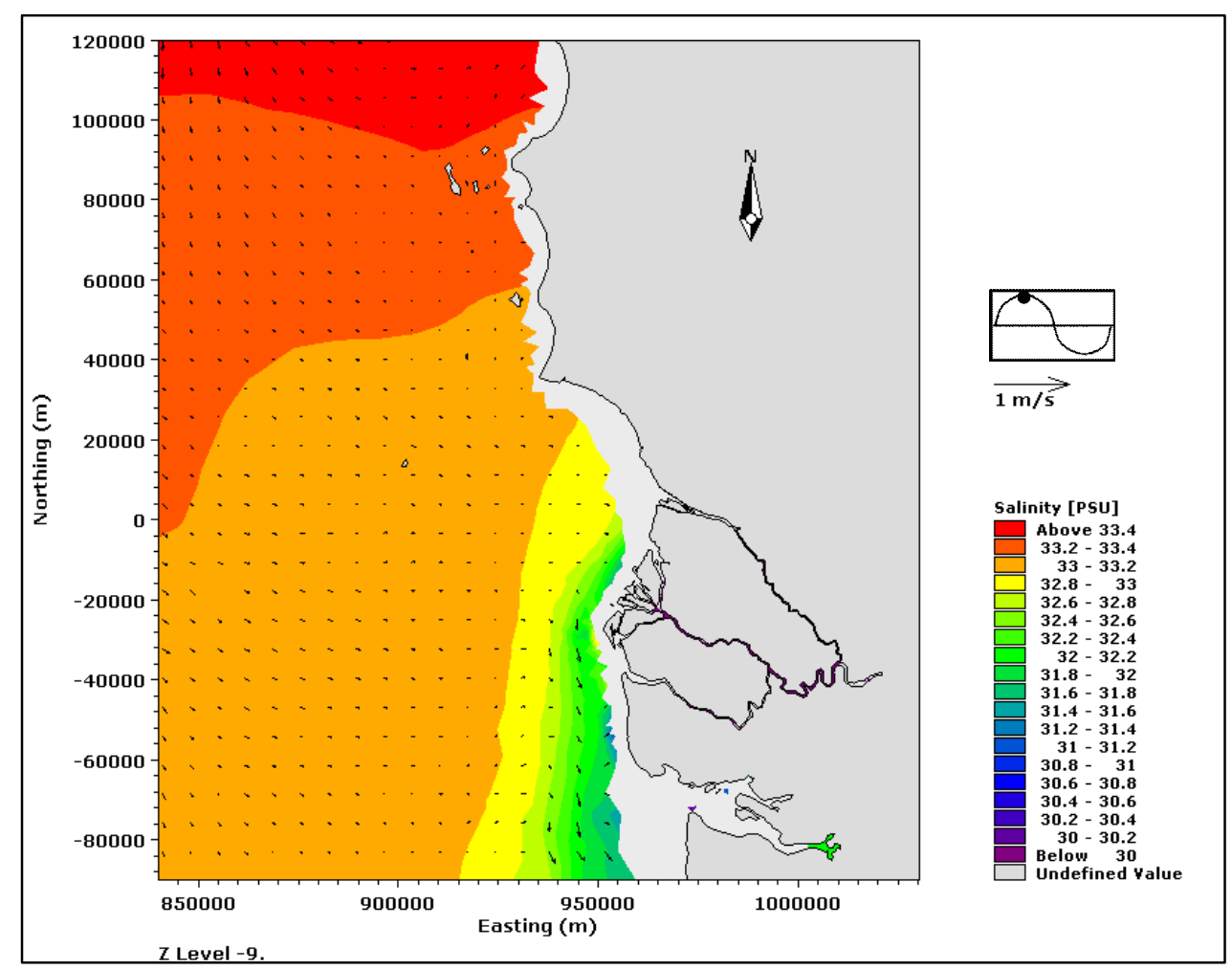

Gambar 6. Pola sirkulasi arus dan sebaran salinitas pada saat air pasang tertinggi perbani pada $0.2 \mathrm{~h}$ (bulan Januari)

\section{b. Surut terendah perbani}

Pada keadaan surut terendah perbani, pola sirkulasi arus di daerah model terbagi atas dua arah sirkulasi yang bersumber dari pergerakan massa air dari arah barat ke timur di daerah sekitar ekuator. Pergerakan massa air ini sebagian bergerak ke arah utara daerah model dan sebagiannya lagi bergerak ke arah selatan dengan kecepatan $0,05 \mathrm{~m} / \mathrm{s}$ s.d 0,15 $\mathrm{m} / \mathrm{s}$. Pola sirkulasi ini jauh berbeda di bandingkan kondisi pasut yang telah di bahas di atas (Gambar 7).
Sebaran salinitas pada saat pasang terendah perbani menunjukkan pola distribusi yang sama dengan kondisi pasang tertinggi perbani (Gambar 7). 


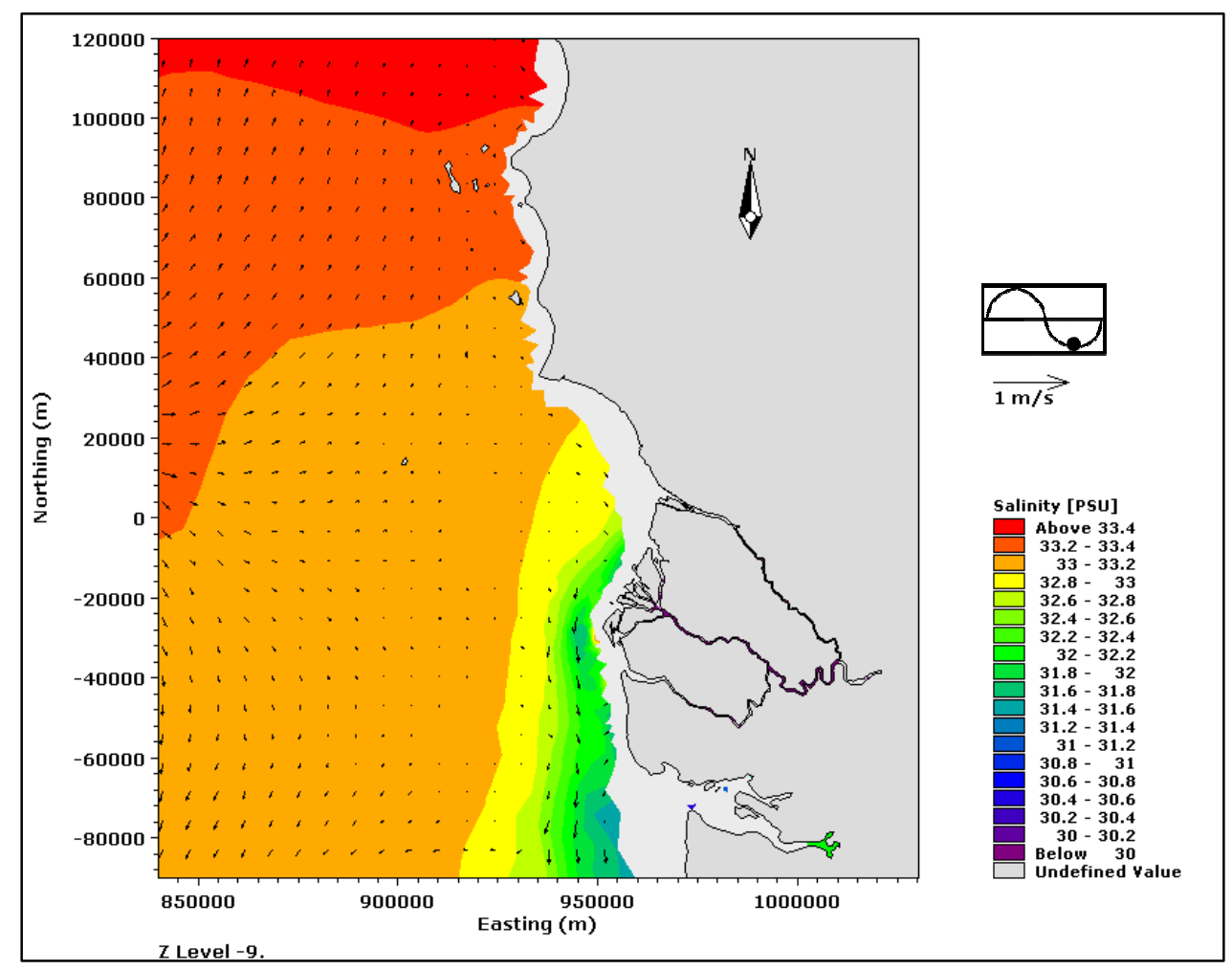

Gambar 7. Pola sirkulasi arus dan sebaran salinitas pada saat air surut terendah perbani pada $0.2 \mathrm{~h}$ (bulan Januari)

\section{Kesimpulan}

a. Pola sirkulasi arus saat purnama maupun perbani menunjukkan kesesuaian pola, yang membedakan adalah besarnya kecepatan arus (kecepatan arus pada kondisi purnama lebih tinggi dibandingkan saat perbani) dengan nilai kecepatan arus $0,05 \mathrm{~m} / \mathrm{s} \mathrm{s.d} 0,7 \mathrm{~m} / \mathrm{s}$.

b. Pada kondisi pasut yang sama, pola sebaran salinitas juga cenderung sama.

c. Salinitas perairan daerah model lebih tinggi pada saat perbani (lebih besar dari 33 PSU) dibandingkan pada saat purnama (kurang dari 30 PSU)

\section{Daftar Pustaka}

1. Ditjen Pembangunan Daerah, Depdagri, "Pedoman Perencanaan dan Pengelolaan Pesisir Terpadu", 1998.

2. Hadi, S., N. S. Ningsih, A. Tarya, Study in sesional Variation of Cohecive Suspended Sediment Transport in Estuari of Mahakam Delta by Using a Numerical Model, Jurnal Teknik Sipil, Vol. 13, No. 1, Januari 2006
3. Jumarang, M. I., Muliadi, Ihwan, A., 2008, "Pola sirkulasi Arus Tiga Dimensi Perairan Pantai Kalimantan Barat, Journal Aplikasi Fisika FMIPA Haluoleo University, Vol. 4 No.1, hal. 1-9

4. Ningsih, N. S., B. Priyono, S. Hadi, dan A. Tarya, "Studi Awal Pemodelan Numerik Transpor Sedimen 2D Horisontal di Estuari Mahakam, Jurnal Teknologi Mineral, Vol. XIV, No.2, 2007

5. Pathirana, K. P. P., Yu, C. S., and Berlamont, J., "Modelling Cohesive Sediment Transport in Tidal Waters", Hydro-Port 94, International Conference on HydroTechnical Engineering for Port and Harbor Construction. Yokosuka, Japan, October 19-21, 1994.

6. Simpson, J.H., "Physical Processes in the ROFI Regime", Journal of Marine Systems 12, 1997.

7. Supriharyono,"Pelestarian dan Pengelolaan Sumber Daya Alam di Wilayah Pesisir Tropis":, PT. Gramedia Pustaka Utama, 2000.

8. Uncles, R. J., and Stephens, J. A., "Sediment Transport in the Humber-Ouse Estuary, UK, during May 1994", Physics of Estuary and Coastal Seas, Dronkers \& Scheffers (eds) Balkema, Rotterdam, 1998. 